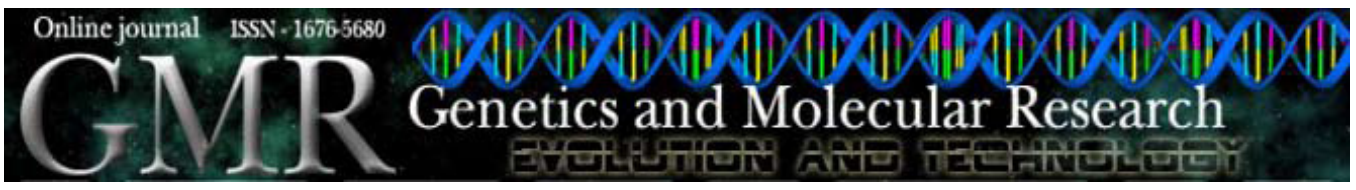

\title{
Investigation of mutations associated with pyrethroid resistance in populations of the New World Screwworm fly, Cochliomyia hominivorax (Diptera: Calliphoridae)
}

\author{
N.M. da Silva ${ }^{1,2}$ and A.M.L. de Azeredo-Espin ${ }^{1,2}$ \\ ${ }^{1}$ Laboratório de Genética Animal, \\ Centro de Biologia Molecular e Engenharia Genética, \\ Universidade Estadual de Campinas, Campinas, SP, Brasil \\ ${ }^{2}$ Departamento de Genética e Evolução, Instituto de Biologia, \\ Universidade Estadual de Campinas, Campinas, SP, Brasil \\ Corresponding author: N.M. da Silva \\ E-mail: normams@unicamp.br/normamsilva@yahoo.com.br
}

Genet. Mol. Res. 8 (3): 1067-1078 (2009)

Received May 10, 2009

Accepted June 23, 2009

Published September 1, 2009

\begin{abstract}
Cochliomyia hominivorax larvae are known for their parasitic habit in living vertebrates, causing considerable economic losses to livestock industry. This ectoparasite has been controlled mainly by applying insecticides, but this method usually results in the selection of resistant individuals. The resistance mechanism known as knockdown resistance (kdr) is a generic term for amino acid substitutions in the sodium channel associated with pyrethroid resistance, and substitutions in residue 251 of the carboxylesterase E3 have been associated with organophosphate and pyrethroid hydrolysis. We looked for L1014F $\mathrm{kdr}$ and W251S mutations in the sodium channel and E3 genes, respectively, in C. hominivorax populations. Ten populations obtained from its current distribution were investigated using the polymerase chain reaction-restriction fragment length polymorphism technique. No mutant individuals were found for the kdr mutation. However, the W251S mutation was found in all populations investigated. Results from
\end{abstract}


a bioassay with cypermethrin (a pyrethroid) indicated that the survival at the lowest concentration (Fisher exact test, $\mathrm{P}=0.0003$ ) and an intermediate concentration $(\mathrm{P}=0.024)$ were associated with the W251S mutation. This correlation was not significant at the highest concentration tested $(\mathrm{P}=0.221)$. We suggest that the $\mathrm{W} 251 \mathrm{~S}$ mutation in the $C$. hominivorax carboxylesterase E3 is also associated with pyrethroid hydrolysis. This information may contribute to the elaboration of improved management programs for this ectoparasite.

Key words: Cochliomyia hominivorax; Insecticide resistance; kdr; Carboxylesterase

\section{INTRODUCTION}

The New World screwworm fly, Cochliomyia hominivorax (Coquerel), is one of the most important myiasis-causing flies in Neotropical regions. C. hominivorax myiasis is caused by the larval stage infesting tissues of warm-blooded vertebrates (Hall and Wall, 1995). This species represents a serious threat to the livestock industry throughout its current distribution, which includes some Caribbean islands and South America (except for Chile) (Vargas-Terán et al., 2005). The sterile insect technique was used to eradicate $C$. hominivorax from both North and Central America (Wyss, 2000), and after an outbreak in Libya, North Africa (Lindquist et al., 1992).

In some South American countries, such as Brazil and Venezuela, this fly has been controlled by applying insecticides, mainly organophosphate (OP) compounds (SINDAN, 2009; Coronado and Kowalski, 2009). In Brazil, some insecticides are currently being applied as a combination of $\mathrm{OP}$ and pyrethroid compounds, using increasingly greater concentrations of pyrethroids. This has probably been carried out as an alternative for the more efficient control of this ectoparasite, since OP insecticides have been used for decades, and a mutation in the carboxylesterase E3 gene (G137D) associated with OP resistance has been found in several regions (de Carvalho et al., 2006). In Uruguay, where there is intense use of insecticides for myiasis control in sheep, pyrethroid compounds are used extensively (Veterinary Products Control Department of DILAVE, Ministerio de Ganadería, Agricultura y Pesca del Uruguay).

The continuous and improper use of insecticides can result in the selection of resistant individuals, but little is known about insecticide resistance in the New World screwworm fly. One of the major mechanisms of insecticide resistance involves metabolic detoxification of the insecticide before it reaches its target site. The three major enzyme families implicated in this mechanism are cytochrome P450s, carboxylesterases and glutathione-S-transferases (Ranson et al., 2002). Structural mutations in specific carboxylesterases have been found in the active degradation mechanism, which convert the enzymatic activity to an OP hydrolase (Newcomb et al., 1997). Carboxylesterase E3 variants from resistant strains of the sheep blowfly Lucilia cuprina (Calliphoridae) have shown a substitution of glycine to aspartate at residue 137 (G137D), which enhances OP hydrolase activity, mainly for diethyl-OP. Substitution of tryptophan by leucine or serine at residue 251 (W251L or W251S) also confers resistance to OP, mainly dimethyl-OP (Campbell et al., 1998). Furthermore, it has been demonstrated recently that substitutions at residue 251 of the E3 protein of L. cuprina and Drosophila me- 
lanogaster, produced by in vitro mutagenesis, also confer pyrethroid-hydrolyzing capacity (Heidari et al., 2005).

Another important resistance mechanism is the alteration of the target molecule in such a way that it becomes insensitive to the insecticides (Oakeshott et al., 2003). Insecticide target-site genes have been cloned from a range of pest insects and the resistance-associated mutations compared. These studies have shown that despite the wide range of insects studied and differences in the modes of insecticide selection, the same amino acid residues are consistently replaced in the same receptors and/or enzymes, demonstrating the existence of a limited number of possible substitutions (ffrench-Constant et al., 1998; Davies et al., 2007).

The "knockdown resistance" $(\mathrm{kdr})$ mechanism is a generic term that is associated with resistance to pyrethroids, which involves amino acid substitutions in the voltage-sensitive sodium channel, causing a reduction in the sensitivity of the insect nervous system to pyrethroids (Soderlund and Knipple, 2003). The most common mutation involves a substitution of leucine by phenylalanine (L1014F, position according to sequence of amino acids in Musca domestica; Williamson et al., 1996), and it is found in different insect species (Davies et al., 2007). In pyrethroid-susceptible strains of different insect species, the CTT triplet determines the amino acid leucine in the equivalent position 1014 of the sodium channel protein. In pyrethroid-resistant strains of $M$. domestica, Haematobia irritans and other insect species, the substitution occurs in the first position of the triplet (TTT) causing a change to phenylalanine. The occurrence of the kdr phenotype is likely to be strongly influenced by codon constraints. Amino acid substitutions that can be brought about by a single-step mutation are much more likely to occur (review in Davies et al., 2007).

Considering this scenario and the economic importance of this fly to the livestock industry, two molecular mechanisms of pyrethroid resistance were investigated in C. hominivorax. The mutations in the sodium channel and carboxylesterase E3 genes were analyzed in individuals obtained from its current geographic distribution. The aim of this study was to verify the resistance mechanisms that are being selected from different regions where this species occurs. The determination of occurrence and frequency of these mechanisms in the different regions may contribute to the understanding of resistance evolution in this ectoparasite and, consequently, to future area-wide integrated pest management programs.

\section{MATERIAL AND METHODS}

\section{Populations sampled and DNA extraction}

Cochliomyia hominivorax samples were collected as larvae in infested animals and preserved in absolute ethanol until DNA extraction. Only one population (Estiva, Minas Gerais, Brazil) was brought to the laboratory and maintained to perform the bioassay. The localities sampled were Pinheiro Machado (Rio Grande do Sul, Brazil); Carambeí (Paraná, Brazil), Estiva (Minas Gerais, Brazil); Caiapônia (Goiás, Brazil); Santa Maria das Barreiras (Pará, Brazil); Bañados de Medina (Uruguay); Ybytymi (Paraguay); Encontrados (Venezuela); Turbo (Colombia), and Ciego de Ávila (Cuba). For each population, 15-17 individuals, from at least 10 wounds, were analyzed to determine the presence of mutations. DNA from larvae was extracted using the phenol-chloroform method, according to Vargas and Espin (1995). 


\section{PCR-RFLP and allele-specific PCR techniques to investigate the kdr mutation}

Primers were designed based on sequences of the sodium channel gene of D. melanogaster (M32078), M. domestica (X96668) and H. irritans (U83872), obtained from GenBank. The primers R1N (5' TCCATGTGGGACTGCATGT 3') and R2N (5' ACTGATCTGGTTGATCCTCTCA 3') were used to amplify a fragment of $383 \mathrm{bp}$ in C. hominivorax, including the region of the L1014F mutation (data not shown). The amplified fragment, from individuals from different regions, was purified on a $1 \%$ agarose gel using the QIAquick Gel Extraction Kit (Qiagen) and cloned using the TA Cloning Kit (Invitrogen). Sequencing was performed with the Big Dye ${ }^{\mathrm{TM}}$ Terminator Cycle Sequencing Ready Kit, version 3.0 (ABI Prism ${ }^{\mathrm{TM}}$, Perkin Elmer) and the ABI 3700 automatic sequencer (Perkin Elmer Applied Biosystems). For each individual, three clones were sequenced, and the sequences were submitted to Blastn search to confirm the identity of the amplicon. The sequence of the $C$. hominivorax sodium channel was submitted to GenBank (EU350483).

Using the sequence obtained, C. hominivorax-specific primers R1N2 (5' TCCATGTGGGATTGTATGTATG 3') and R2N2 (5' CGGCAATATTACGTTTCACC $3^{\prime}$ ) were designed to amplify an internal region (303 bp) to be used in the polymerase chain reaction-restriction fragment length polymorphism (PCR-RFLP) technique. The amplifications were conducted in a final reaction volume of $15 \mu \mathrm{L}$ under the following conditions: $25-100 \mathrm{ng}$ genomic DNA, $0.3 \mu \mathrm{M}$ of the primers, $1.3 \mathrm{mM} \mathrm{MgCl}_{2}, 1$ unit Taq DNA Polymerase (Invitrogen), $1.5 \mu \mathrm{L} 10 \mathrm{X}$ buffer (200 mM Tris- $\mathrm{HCl}, \mathrm{pH} 8.4,500 \mathrm{mM}$ $\mathrm{KCl}), 0.1 \mathrm{mM}$ of each dNTP and $0.5 \mathrm{mg} / \mathrm{mL}$ BSA. PCR was performed in a PTC $200 \mathrm{MJ}$ Research thermal cycler. After an initial denaturing step of 2 min at $94^{\circ} \mathrm{C}, 35$ cycles were performed, each one consisting of $50 \mathrm{~s}$ at $94^{\circ} \mathrm{C}, 50 \mathrm{~s}$ at $56^{\circ} \mathrm{C}$ and $30 \mathrm{~s}$ at $72^{\circ} \mathrm{C}$, with a final extension step of $20 \mathrm{~min}$ at $72^{\circ} \mathrm{C}$.

Since the L1014F mutation causes a new enzyme restriction site, the endonuclease Tsp509I (New England BioLabs) was used to digest the PCR products, according to manufacturer instructions, allowing the visualization of a diagnostic fragment for the presence of mutation. The digested products were visualized on a 10\% acrylamide gel, after staining with silver nitrate $\left(\mathrm{AgNO}_{3}\right)$, to better separate and visualize the diagnostic fragment for the presence of mutation.

Alternatively, allele-specific PCR (ASPCR), a faster method to screen individuals, was also standardized in C. hominivorax. The kdrW (5'GCCACAGTAGTTATCGGCAAT $\underline{\text { }}$ 3') and kdrM (5' GCCACAGTAGTTATCGGCAATT 3') primers were designed based on previous sequences obtained from $C$. hominivorax. These primers differ from each other only in their last nucleotide (underlined). For the ASPCR, each complete assay required two amplification reactions, one reaction to detect the wild-type allele (kdrW/ R2N2), and a second to detect the mutant allele ( $\mathrm{kdrM} / \mathrm{R} 2 \mathrm{~N} 2)$. In both reactions, the R1N2/R2N2 combination primers amplify a control fragment for PCR (Figure 1). The amplifications were conducted in a final reaction volume of $15 \mu \mathrm{L}$ under the following conditions: $25-100 \mathrm{ng}$ genomic DNA, $0.25 \mu \mathrm{M}$ R1N2 primer and $0.3 \mu \mathrm{M}$ R2N2, kdrW or kdrM primers, $1.3 \mathrm{mM} \mathrm{MgCl}, 1$ unit Taq DNA Polymerase (Invitrogen), $1.5 \mu \mathrm{L} \mathrm{10X}$ buffer (200 mM Tris-HCl, pH 8.4, $500 \mathrm{mM} \mathrm{KCl),} 0.1 \mathrm{mM}$ of each dNTP and $0.5 \mathrm{mg} / \mathrm{mL}$ 


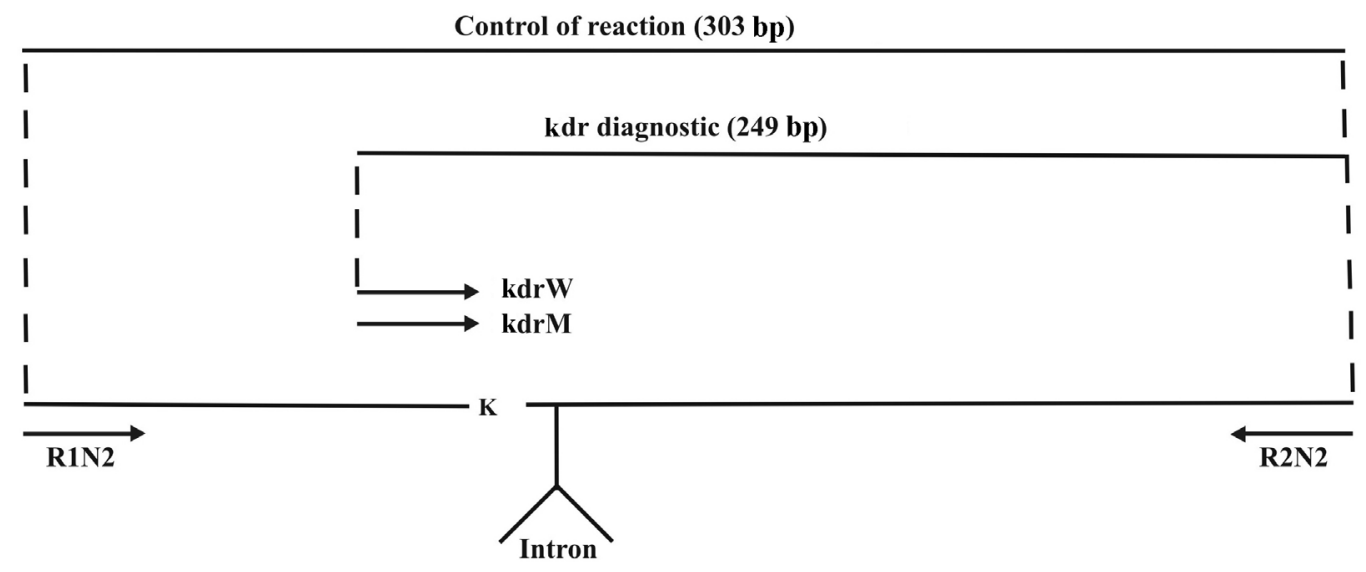

Figure 1. Schematic view of allele-specific polymerase chain reaction strategy with the L1014F kdr mutation site designated as K. Primers are shown as arrows with their directions indicating the direction of primer extension. The intron is amplified in the control and diagnostic fragments, and the length of fragments is indicated.

BSA. PCR was performed in a PTC 200 MJ Research thermal cycler. After an initial denaturing step of $2 \mathrm{~min}$ at $94^{\circ} \mathrm{C}, 35$ cycles were performed, each one consisting of 50 $\mathrm{s}$ at $94^{\circ} \mathrm{C}, 50 \mathrm{~s}$ at $56^{\circ} \mathrm{C}$ and $30 \mathrm{~s}$ at $72^{\circ} \mathrm{C}$, with a final extension step of $20 \mathrm{~min}$ at $72^{\circ} \mathrm{C}$.

\section{Detection of W251S mutation in E3 gene}

TheFlaN(5'GGCTCCAGAAACTAAACG3')andR3a(5'ATCCTTATCATTATTTTCACCC 3') primers were designed using the sequence of carboxylesterase $\mathrm{E} 3$ gene of $C$. hominivorax (Carvalho et al., 2009), and used to amplify a fragment that contains position 251 . The conditions of the $15-\mu \mathrm{L}$ reaction mix were: $25-100 \mathrm{ng}$ genomic DNA, $0.2 \mu \mathrm{M}$ of each primer, $2.5 \mathrm{mM} \mathrm{MgCl}, 2$ units Taq Polymerase (Invitrogen), $1.5 \mu \mathrm{L} 10 \mathrm{X}$ buffer (200 mM Tris-HCl, pH 8.4, $500 \mathrm{mM} \mathrm{KCl}$ ), $0.2 \mathrm{mM}$ of each dNTP and $0.5 \mathrm{mg} / \mathrm{mL}$ BSA. PCR was performed in a PTC $200 \mathrm{MJ}$ Research thermal cycler. After an initial denaturing step of $2 \mathrm{~min}$ at $94^{\circ} \mathrm{C}, 35$ cycles were performed, each one consisting of $50 \mathrm{~s}$ at $94^{\circ} \mathrm{C}, 50 \mathrm{~s}$ at $53^{\circ} \mathrm{C}$ and $1 \mathrm{~min}$ at $72^{\circ} \mathrm{C}$, with a final extension step of $20 \mathrm{~min}$ at $72^{\circ} \mathrm{C}$. To apply the PCRRFLP technique, the endonuclease StyI (New England BioLabs) was used to digest the PCR products according to manufacturer instructions. This enzyme cleaves the wild-type sequence. The digested fragments were visualized on a $1.5 \%$ agarose gel, after staining with ethidium bromide.

\section{Bioassay}

The bioassay was conducted with the F7 laboratory generation of a $C$. hominivorax population from Estiva (Minas Gerais, Brazil), a region of extensive cattle breeding for milk production. The aim of this exploratory bioassay was to identify any relation between the presence of mutant alleles, for one or both mutations investigated, and pyrethroid resistance. Second-instar larvae were exposed to four cypermethrin concentrations: $37.5 \times 10^{-12}, 7.5 \times 10^{-12}$, $3.7 \times 10^{-12}$, and $1.8 \times 10^{-12} \mu \mathrm{g} / \mathrm{mL}$. The insecticide was mixed in the larval rearing medium, consisting of $60 \mathrm{~g}$ ground meat and $20 \mathrm{~mL}$ blood (bovine). Three replicates of 50 larvae were used 
for each concentration, and for control samples without insecticide. Mortality was assessed immediately after exposure to the insecticide to check for any early mortality caused by larval manipulation, and after 12-h exposure. The criterion established for death was the inability of the larvae to move after being prodded. In order to verify the presence of the L1014F mutation in the sodium channel and the W251S mutation in carboxylesterase E3, samples of individuals of three of the four cypermethrin concentrations tested were analyzed. Five alive and five dead individuals of each replicate were analyzed, totaling thirty individuals per concentration (fifteen alive and fifteen dead), except for the highest concentration, where twenty individuals (five alive and fifteen dead) were analyzed. Results were analyzed by the Fisher exact test, using the Statistica 6.0 software (Statsoft, 2001).

\section{RESULTS AND DISCUSSION}

As reported for other insect species, the same CTT triplet determines the amino acid leucine in the equivalent position 1014 of the sodium channel protein in the $C$. hominivorax (data not shown), and a single-step mutation would allow the substitution to a phenylalanine, which may be selected by the use of pyrethroids. The frequencies of L1014F and W251S mutations in the C. hominivorax populations are presented in Table 1. For the kdr mutation (L1014F), no mutant individuals were found in any of the populations investigated (note in Figure 2A the absence of a 72-bp fragment that is diagnostic for the presence of mutation). Although the L1014F kdr mutation appears to be a common mechanism associated with pyrethroid resistance in other species, the absence of this mutation in our analysis may mean that this variation did not arise in C. hominivorax populations, or that with our sampling we were unable to detect this mutation.

\begin{tabular}{|c|c|c|c|c|c|c|c|}
\hline \multirow{3}{*}{ Populations } & \multirow{3}{*}{$\mathrm{N}$} & \multirow{3}{*}{ Latitude/Longitude } & \multirow{3}{*}{$\begin{array}{l}\text { kdr mutation } \\
\text { frequency }(\%)\end{array}$} & \multicolumn{4}{|c|}{ W251S mutation } \\
\hline & & & & \multicolumn{3}{|c|}{ Frequency of genotypes } & \multirow{2}{*}{$\begin{array}{l}\text { Mutant allele } \\
\text { frequency }(\%)\end{array}$} \\
\hline & & & & MM & WW & MW & \\
\hline Pinheiro Machado (Brazil) & 16 & $31^{\circ} 34 \mathrm{~S} / 53^{\circ} 23 \mathrm{~W}$ & 0 & 0 & 11 & 5 & 15.62 \\
\hline Carambeí (Brazil) & 16 & $24^{\circ} 55 \mathrm{~S} / 50^{\circ} 05 \mathrm{~W}$ & 0 & 0 & 4 & 12 & 37.50 \\
\hline Estiva (Brazil) & 15 & $22^{\circ} 27 \mathrm{~S} / 46^{\circ} 01 \mathrm{~W}$ & 0 & 3 & 4 & 8 & 46.67 \\
\hline Caiapônia (Brazil) & 15 & $16^{\circ} 57 \mathrm{~S} / 51^{\circ} 48 \mathrm{~W}$ & 0 & 2 & 6 & 7 & 36.67 \\
\hline Santa Maria das Barreiras (Brazil) & 17 & $08^{\circ} 52 \mathrm{~S} / 49^{\circ} 42 \mathrm{~W}$ & 0 & 1 & 5 & 11 & 38.23 \\
\hline Bañados de Medina (Uruguay) & 16 & $32^{\circ} 23 \mathrm{~S} / 54^{\circ} 21 \mathrm{~W}$ & 0 & 1 & 8 & 7 & 28.12 \\
\hline Ybytymi (Paraguay) & 15 & $25^{\circ} 46 \mathrm{~S} / 56^{\circ} 41 \mathrm{~W}$ & 0 & 2 & 3 & 10 & 46.67 \\
\hline Encontrados (Venezuela) & 16 & $09^{\circ} 03 \mathrm{~N} / 72^{\circ} 14 \mathrm{~W}$ & 0 & 16 & 0 & 0 & 100 \\
\hline Turbo (Colombia) & 16 & $08^{\circ} 05 \mathrm{~N} / 76^{\circ} 43 \mathrm{~W}$ & 0 & 14 & 0 & 2 & 93.75 \\
\hline Ciego de Ávila (Cuba) & 15 & $21^{\circ} 50 \mathrm{~N} / 78^{\circ} 46 \mathrm{~W}$ & 0 & 0 & 10 & 5 & 16.67 \\
\hline
\end{tabular}

$\mathrm{MM}=$ mutant homozygote; $\mathrm{WW}=$ wild-type homozygote; $\mathrm{MW}=$ heterozygote; $\mathrm{N}=$ total number of individuals analyzed.

Besides PCR-RFLP, ASPCR was also standardized in C. hominivorax as an alternative technique to screen individuals rapidly (Figure $2 \mathrm{~B}$ ). Since kdr mutant individuals were not found, the ASPCR was applied in a mutant strain of $M$. domestica (kdr-579, mutant homozygous for kdr; Farnham et al., 1987) to test this method in detecting the mutant allele 

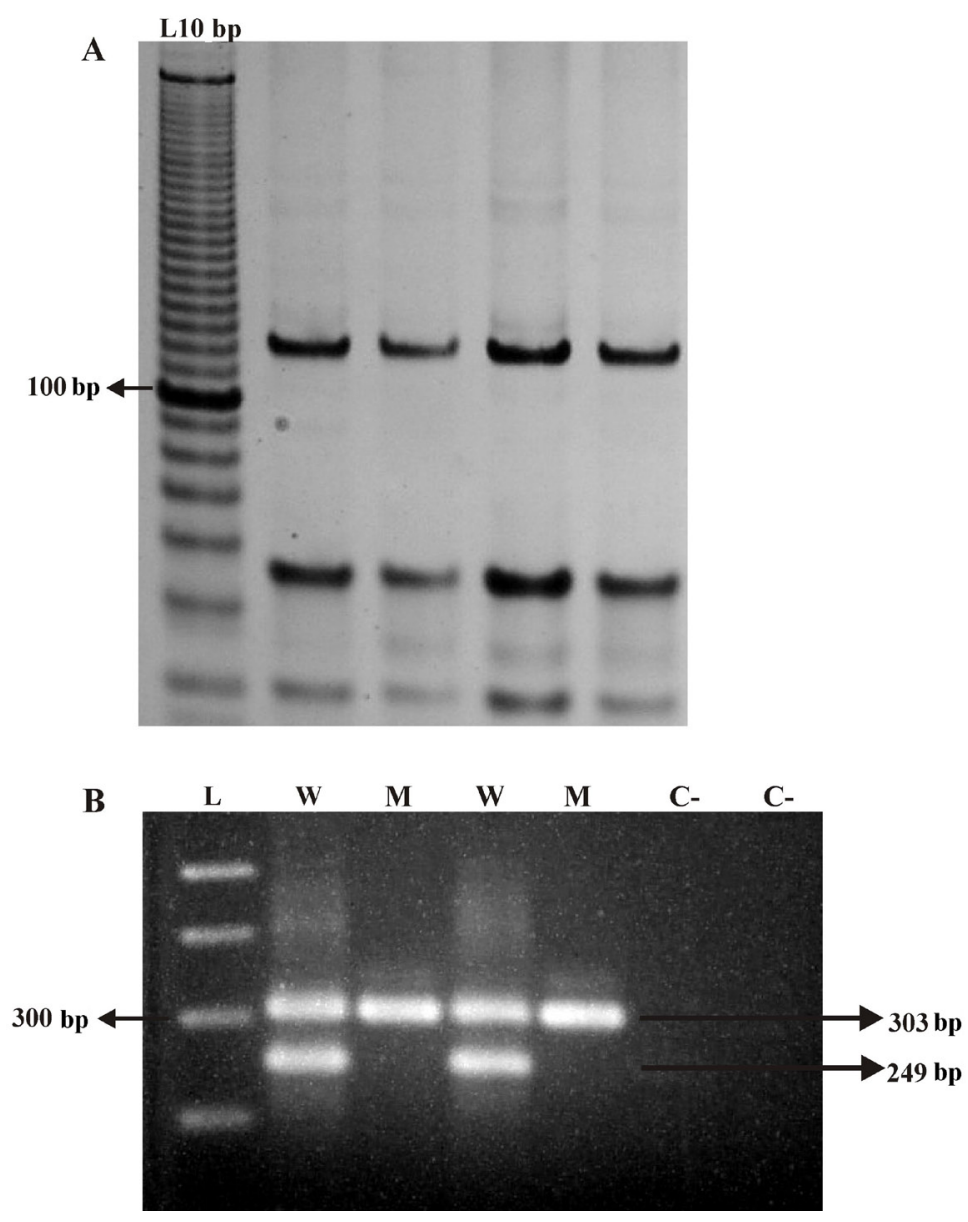

Figure 2. A. Polymerase chain reaction-restriction fragment length polymorphism result to detect the L1014F kdr mutation in Cochliomyia hominivorax samples. All individuals are wild-type (genotype is deduced by the absence of a fragment of $72 \mathrm{bp}$ ). L10 bp $=10$-bp DNA ladder. B. Allele-specific polymerase chain reaction result for Cochliomyia hominivorax samples. For each sample two reactions were performed, where $\mathrm{W}$ is the reaction to detect the wild-type allele, and $\mathrm{M}$ is the reaction to detect the mutant allele. $\mathrm{C}$ - = negative control. $\mathrm{L}=1-\mathrm{kb}$ DNA plus ladder. The lengths of control and diagnostic fragments are 303 and 249 bp, respectively, as shown in Figure 1.

(data not shown). Despite using DNA from $M$. domestica, the conditions of amplification for the ASPCR were the same used for C. hominivorax, demonstrating that ASPCR, used under standardized conditions, is also able to identify the mutant allele.

In contrast to the kdr mutation, the W251S mutation in the $\mathrm{E} 3$ gene of $C$. hominivorax was found in different frequencies in the populations analyzed (Table 1). The amplified fragment of $531 \mathrm{bp}$, digested with the endonuclease StyI, showed three different band patterns, representing the three different genotypes, mutant and wild-type homozygotes and heterozygotes (Figure 3). All mutant individuals showed the same substitution (guanine to cytosine in the second position), causing a change of tryptophan (W) to serine (S) in the respective codon. 


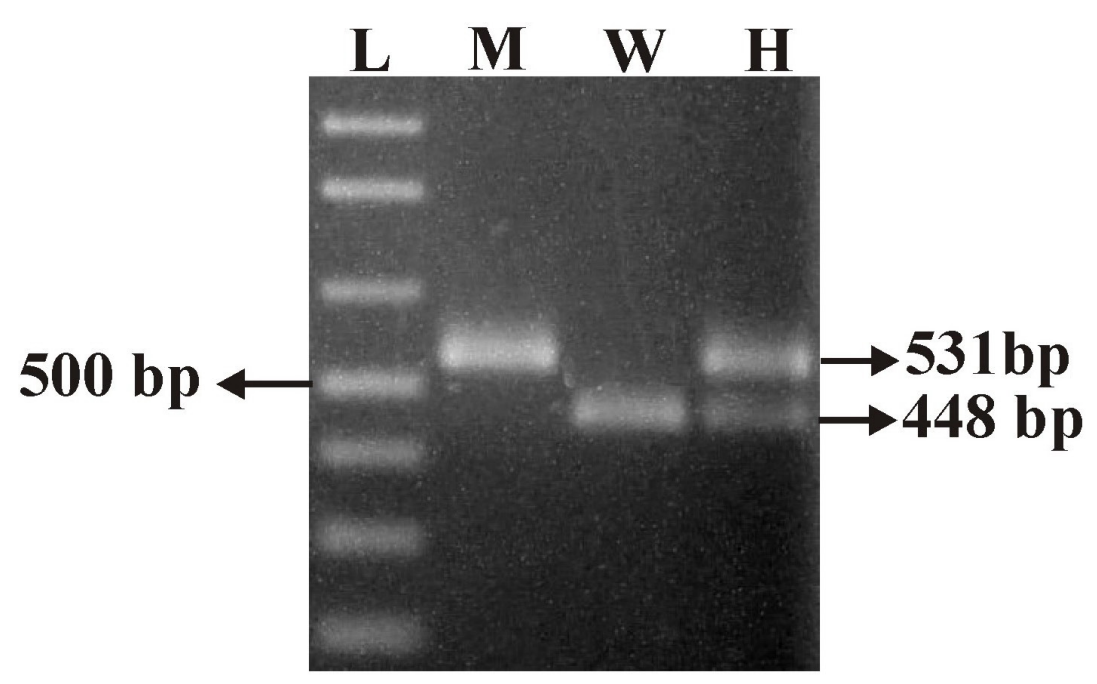

Figure 3. Polymerase chain reaction-restriction fragment length polymorphism to detect the W251S mutation in the $\mathrm{E} 3$ gene of Cochliomyia hominivorax individuals. $\mathrm{M}=$ mutant; $\mathrm{W}=$ wild-type; $\mathrm{H}=$ heterozygote. $\mathrm{L}=1-\mathrm{kb}$ DNA plus ladder.

Mutations of tryptophan to leucine or serine in this residue, related to OP resistance, especially malathion, are well characterized in L. cuprina (Campbell et al., 1998) and M. domestica (Taskin and Kence, 2004), respectively.

However, recent studies, using in vitro site-directed mutagenesis in L. cuprina, showed that different substitutions in the residue W251 (S,T,G,A) increased pyrethroid hydrolysis, with W251L having the greatest effect (Heidari et al., 2005; Devonshire et al., 2007). This residue is localized in a region that is considered to be a subsite (acyl-binding pocket) of the active site of E3 enzyme, and all these substitutions are to smaller residues, which make the acyl-binding pocket larger and therefore more able to accommodate the bulky acyl groups of the synthetic pyrethroids and their analogs (Devonshire et al., 2007). The W251L substitution in the D. melanogaster orthologue gene also increased pyrethroid hydrolysis (Heidari et al., 2005). Some studies have demonstrated that the role of carboxylesterases in resistance, including cross-resistance, may originate from over-expression and point mutations in esterase-coding genes (Brogdon and Barber, 1990; Chen and Sun, 1994; Bisset et al., 1997; Baffi et al., 2007).

In Brazilian C. hominivorax populations, the highest allelic frequency $(46.67 \%)$ found for the W251S mutation was in the sample from Estiva (Minas Gerais), and the lowest frequency $(15.62 \%)$ was found for the samples from Pinheiro Machado (Rio Grande do Sul) (Table 1). In addition to the selection pressure by the use of OP insecticides, this mutation could be selected by the use of pyrethroid compounds.

In Uruguay, the use of pyrethroids to control myiasis-causing flies seems to be more common, but the frequency found for the mutant allele was noted to be $28.12 \%$ (Table 1). However, no information could be found regarding how long pyrethroid insecticides have been used. Populations from Venezuela and Colombia displayed the highest 
frequencies of W251S mutation, 100 and $93.75 \%$, respectively (Table 1). A curious result obtained was the heterozygote deficit observed for the W251S mutation in these countries (Table 1). Based on our data, we were unable to formulate a conclusive explanation for this, but naturally, we cannot ignore the possible Wahlund effect, because of sampling strategy in these countries (the samples of these two localities were obtained from veterinary clinics). Therefore, it is possible that two different subpopulations were evaluated, instead of one, in these localities. In Cuba, the official register for the presence of $C$. hominivorax was carried out only in 1995, and until recently, lindane (a GABA inhibitor) was used to control this fly (FAO, 1999). These facts and the probable recent use of OP or pyrethroid compounds to control myiasis-causing flies may explain the low frequency of W251S mutation in that country (Table 1). Except for Brazil, only one population of each country was investigated as a preliminary survey. An analysis of other populations may contribute to obtaining a more exact profile of insecticide resistance in this ectoparasite in the South America and Caribbean region.

The development of different mechanisms of insecticide resistance depends on biological, genetic and ecological factors, besides the management tactics used in each region (Guerrero and Barros, 2006). The results found for the populations analyzed are related to management tactics for livestock in different regions, which include the class of insecticide used, time of use, and method and frequency of the applications, as well as the frequent use of suboptimal doses and concentrations. Unfortunately, it is very difficult to obtain information from government agencies regarding the management tactics to control this ectoparasite in the different regions analyzed. However, the monitoring of common mechanisms for different species may provide interesting information for the investigation of the evolution and spread of well-characterized resistance genes.

Considering the association of W251S with pyrethroid hydrolysis (Heidari et al., 2005; Devonshire et al., 2007), its presence in all populations investigated and the absence of L1014F kdr mutation, a bioassay was conducted to investigate if the presence of this mutation in the $\mathrm{E} 3$ gene of $C$. hominivorax really confers a greater chance of survival in the presence of a pyrethroid insecticide. The percentage of survival for each concentration is presented in Table 2. No difference among replicates was observed, and the highest concentration killed the majority of individuals ( $96.7 \%$ mortality). Despite the 2 -fold difference between the two lowest concentrations, the survival was similar for both (Table 2). None of the individuals analyzed showed the L1014F kdr mutation, but the presence of W251S mutation was found in individuals from the three concentrations analyzed (Table $3)$. The Fisher exact test was applied to determine if the presence of mutant allele was significantly correlated with survival in the presence of insecticide. For that, the number

\begin{tabular}{l} 
Table 2. Susceptibility of Cochliomyia hominivorax larvae to cypermethrin for each concentration tested (with \\
three replicates, and with 50 larvae each, totaling 150 larvae per concentration). \\
\hline \begin{tabular}{lc} 
Cypermethrin $(\mu \mathrm{g} / \mathrm{mL})$ & $\%$ alive individuals \\
\hline $37.5 \times 10^{-12}$ & 3.3 \\
$7.5 \times 10^{-12}$ & 38.0 \\
$3.7 \times 10^{-12}$ & 58.7 \\
$1.8 \times 10^{-12}$ & 64.7 \\
Control & 99.3 \\
\hline
\end{tabular}
\end{tabular}


Table 3. Number of mutant and wild alleles found in dead and alive Cochliomyia hominivorax larvae for the three cypermethrin concentrations analyzed from the bioassay.

\begin{tabular}{|c|c|c|c|c|c|}
\hline \multirow{2}{*}{$\begin{array}{l}\text { Cypermethrin } \\
(\mu \mathrm{g} / \mathrm{mL})\end{array}$} & \multicolumn{2}{|c|}{ Number of mutant alleles } & \multicolumn{2}{|c|}{ Number of wild alleles } & \multirow[t]{2}{*}{$\mathrm{N}$} \\
\hline & Alive & Dead & Alive & Dead & \\
\hline $37.5 \times 10^{-12}$ & 6 & 14 & 4 & 16 & 20 \\
\hline${ }^{a} 7.5 \times 10^{-12}$ & 22 & 14 & 8 & 16 & 30 \\
\hline${ }^{\mathrm{a}} 1.8 \times 10^{-12}$ & 16 & 3 & 14 & 27 & 30 \\
\hline
\end{tabular}

${ }^{\mathrm{a}}$ Fisher exact test: $\mathrm{P}=0.221, \alpha=0.05 ; \mathrm{P}=0.024, \alpha=0.05 ; \mathrm{P}=0.0003, \alpha=0.05$ from the highest concentration to the lowest concentration, respectively. $\mathrm{N}=$ total number of individuals analyzed.

of mutant and wild alleles found in dead and alive individuals for each concentration was considered (Table 3).

At the lowest and intermediate concentrations, the Fisher exact test $(\mathrm{P}=0.0003$, $\alpha=0.05$, and $\mathrm{P}=0.024, \alpha=0.05$, respectively) indicated that the presence of alleles with the W251S mutation is indeed correlated with the chance of survival in the presence of insecticide. This probably occurs because this mutation confers to the enzyme a higher capacity for metabolizing the insecticide (cypermethrin) before it reaches the target site. However, at the highest concentration, the analysis was impaired since only five individuals survived in the three replicates $(\mathrm{P}=0.221, \alpha=0.05$; Fisher exact test). This concentration was probably too high, making it impossible for the insecticide to be completely metabolized, even by mutant individuals. Besides, type II pyrethroids (those having an $\alpha$-cyano group), like cypermethrin, are generally more hard to hydrolysis by invertebrate esterases (review in Heidari et al., 2005).

Considering the use of pyrethroid and/or OP compounds to control myiasis-causing flies in the different regions investigated, the absence of the L1014F kdr mutation, the presence of the W251S mutation in all populations, and the bioassay results, this mutation possibly confers cross-resistance to OP and pyrethroid compounds in C. hominivorax. Additionally, mutations (W251S and G137D) in the E3 gene appear to be one of the main resistance mechanisms selected for $C$. hominivorax. This latter conclusion is reinforced by two facts: the presence, in C. hominivorax samples from South America, of another mutation in the E3 esterase (G137D) (de Carvalho et al., 2006), also associated with OP resistance, and the absence of mutations, associated with OP resistance, in the acetylcholinesterase gene in almost all samples of the same localities investigated herein, with only two mutant individuals found in Pinheiro Machado (Brazil) (Silva NM, Carvalho RA, Azeredo-Espin AML, unpublished results). Since these same amino acid substitutions are also found in the E3 orthologous genes of L. cuprina and M. domestica (Campbell et al., 1998; Taskin and Kence, 2004), this indicates that these mutations may be a common mechanism of resistance, at least, in the order Diptera.

Although the W251S mutation was found in C. hominivorax populations and even though a significant correlation was seen between this mutation and survival in the bioassay, other bioassays (with different populations and pyrethroid compounds) need to be conducted for a better understanding of the role of the W251S mutation in pyrethroid hydrolysis in this species. In further studies, other metabolic mechanisms not investigated herein, such as over-production of enzymes involved in detoxification processes (Vulule 
et al., 1999; Kasai and Scott, 2000; Strode et al., 2008), will be investigated because they may also be acting together to confer some resistance. Another possibility that needs to be investigated is an alternative target site insensitivity mechanism that is mediated by a sodium channel mutation other than the L1014F mutation.

\section{ACKNOWLEDGMENTS}

The authors thank R.A. Rodrigues, S.M. Couto and A.S. Oliveira for their valuable technical assistance and A.C. da Rosa for help in the collection of samples from Estiva (Minas Gerais State, Brazil). We are also grateful to M.L. Lyra and R.A. Carvalho for valuable suggestions regarding the manuscript and data analyses, and the International Atomic Energy Agency (IAEA) for providing the samples from the Caribbean region. Research supported by a grant from Fundação de Amparo à Pesquisa do Estado de São Paulo (FAPESP) to A.M.L.A.E. (grants \#03/01458-9 and \#07/54431-1), and N.M.S. was supported by a fellowship from the Conselho Nacional de Desenvolvimento Científico e Tecnológico (CNPq) (grant \#141277/2005-0).

\section{REFERENCES}

Baffi MA, de Souza GR, Vieira CU, de Sousa CS, et al. (2007). Identification of point mutations in a putative carboxylesterase and their association with acaricide resistance in Rhipicephalus (Boophilus) microplus (Acari: Ixodidae). Vet. Parasitol. 148: 301-309.

Bisset J, Rodriguez M, Soca A, Pasteur N, et al. (1997). Cross-resistance to pyrethroid and organophosphorus insecticides in the southern house mosquito (Diptera: Culicidae) from Cuba. J. Med. Entomol. 34: 244-246.

Brogdon WG and Barber AM (1990). Fenitrothion-deltamethrin cross-resistance conferred by esterases in Guatemalan Anopheles albimanus. Pestic. Biochem. Physiol. 37: 130-139.

Campbell PM, Newcomb RD, Russel RJ and Oakeshott JG (1998). Two different amino acid substitutions in the aliesterase, E3, confer alternative types of organophosphorus insecticide resistance in the sheep blowfly, Lucilia cuprina. Insect Biochem. Mol. Biol. 28: 139-150.

Carvalho RA, Torres TT, Paniago MG and Azeredo-Espin AM (2009). Molecular characterization of esterase E3 gene associated with organophosphorus insecticide resistance in the New World screwworm fly, Cochliomyia hominivorax. Med. Vet. Entomol. 23 (Suppl 1): 86-91.

Chen WL and Sun CN (1994). Purification and characterization of carboxylesterases of a rice brown planthopper, Nilaparvata lugens Stål. Insect Biochem. Mol. Biol. 24: 347-355.

Coronado A and Kowalski A (2009). Current status of the New World screwworm Cochliomyia hominivorax in Venezuela. Med. Vet. Entomol. 23 (Suppl 1): 106-110.

Davies TGE, Field LM, Usherwood PNR and Williamson MS (2007). A comparative study of voltage-gated sodium channels in the Insecta: implications for pyrethroid resistance in Anopheline and other Neopteran species. Insect Mol. Biol. 16: 361-375.

de Carvalho RA, Torres TT and de Azeredo-Espin AM (2006). A survey of mutations in the Cochliomyia hominivorax (Diptera: Calliphoridae) esterase E3 gene associated with organophosphate resistance and the molecular identification of mutant alleles. Vet. Parasitol. 140: 344-351.

Devonshire AL, Heidari R, Huang HZ, Hammock BD, et al. (2007). Hydrolysis of individual isomers of fluorogenic pyrethroid analogs by mutant carboxylesterases from Lucilia cuprina. Insect Biochem. Mol. Biol. 37: 891-902.

FAO (Food and Agriculture Organization) (1999). Programa de cooperación tecnica. Control del gusano barrenador del ganado para apoyar el desarrollo agropecuario. Cuba. Relación final TCP/CUB/6613. FAO, Rome.

Farnham AW, Murray AWA, Sawicki RM, Denholm I, et al. (1987). Characterization of the structure-activity relationship of kdr and two variants of super-kdr to pyrethroids in the housefly (Musca domestica L.). Pest. Manag. Sci. 19: 209-220.

ffrench-Constant RH, Pittendrigh B, Vaughan A and Anthony N (1998). Why are there so few resistance-associated mutations in insecticide target genes? Philos. Trans. R. Soc. Lond B Biol. Sci. 353: 1685-1693.

Guerrero FD and Barros AT (2006). Role of kdr and esterase-mediated metabolism in pyrethroid-resistant populations of Haematobia irritans irritans (Diptera: Muscidae) in Brazil. J. Med. Entomol. 43: 896-901. 
Hall M and Wall R (1995). Myiasis of humans and domestic animals. Adv. Parasitol. 35: 257-334.

Heidari R, Devonshire AL, Campbell BE, Dorrian SJ, et al. (2005). Hydrolysis of pyrethroids by carboxylesterases from Lucilia cuprina and Drosophila melanogaster with active sites modified by in vitro mutagenesis. Insect Biochem. Mol. Biol. 35: 597-609.

Kasai S and Scott JG (2000). Overexpression of cytochrome P450 CYP6D1 is associated with monooxygenase-mediated pyrethroid resistance in house flies from Georgia. Pestic. Biochem. Physiol. 68: 34-41.

Lindquist DA, Abusowa M and Hall MJ (1992). The New World screwworm fly in Libya: a review of its introduction and eradication. Med. Vet. Entomol. 6: 2-8.

Newcomb RD, Campbell PM, Ollis DL, Cheah E, et al. (1997). A single amino acid substitution converts a carboxylesterase to an organophosphorus hydrolase and confers insecticide resistance on a blowfly. Proc. Natl. Acad. Sci. U. S. A. 94: 7464-7468.

Oakeshott JG, Home I, Sutherland TD and Russell RJ (2003). The genomics of insecticide resistance. Genome Biol. 4: 202.

Ranson H, Claudianos C, Ortelli F, Abgrall C, et al. (2002). Evolution of supergene families associated with insecticide resistance. Science 298: 179-181.

SINDAN (2009). Compêndio de Produtos Veterinários. Available at [http://www.cpvs.com.br/cpvs/index.html]. Accessed June 2, 2009

Soderlund DM and Knipple DC (2003). The molecular biology of knockdown resistance to pyrethroid insecticides. Insect Biochem. Mol. Biol. 33: 563-577.

StatSoft, Inc. (2001). Statistica for windows v. 6.0. StatSoft, Tulsa.

Strode C, Wondji CS, David JP, Hawkes NJ, et al. (2008). Genomic analysis of detoxification genes in the mosquito Aedes aegypti. Insect Biochem. Mol. Biol. 38: 113-123.

Taskin V and Kence M (2004). The genetic basis of malathion resistance in housefly (Musca domestica L.) strains from Turkey. Genetika 40: 1475-1482.

Vargas ME and Espin AM (1995). Genetic variability in mitochondrial DNA of the screwworm, Cochliomyia hominivorax (Diptera: Calliphoridae), from Brazil. Biochem. Genet. 33: 237-256.

Vargas-Terán M, Hofmann HC and Tweddle NE (2005). Impact of Screwworm Eradication Programmes Using the Sterile Insect Technique. In: Sterile Insect Technique - Principles and Practice in Area-Wide Integrated Pest Management (Dick VA, Hendrichs J and Robinson AS, eds.). Springer, Netherlands, 629-650.

Vulule JM, Beach RF, Atieli FK, McAllister JC, et al. (1999). Elevated oxidase and esterase levels associated with permethrin tolerance in Anopheles gambiae from Kenyan villages using permethrin-impregnated nets. Med. Vet. Entomol. 13: 239-244.

Williamson MS, Martinez-Torres D, Hick CA and Devonshire AL (1996). Identification of mutations in the housefly para-type sodium channel gene associated with knockdown resistance (kdr) to pyrethroid insecticides. Mol. Gen. Genet. 252: 51-60.

Wyss JH (2000). Screwworm eradication in the Americas. Ann. N. Y. Acad. Sci. 916: 186-193. 